\title{
Improvement in quality of life by surgical management of the ascending aortic aneurysm
}

\author{
Khakimjon Kabuljonovich ABRALOV, Umid Anvarovich MUROTOV and Ravshan Aliyevich IBADOV ${ }^{\star 凶}$ \\ Republican Specialized Scientific and Practical Medical Center for Surgery named after academician V.Vakhidov, Tashkent, Uzbekistan \\ Corresponding author's Email: tmsravshan@mail.ru; (D) ORCID: 0000-0002-0992-0802
}

\section{ABSTRACT}

Aim. The article presents an analysis of the surgical treatment results in 98 patients with ascending aorta aneurysm (AAA), divided into two groups depending on the method of prosthetics. Methods. The main group included 71 patients who underwent surgery according to the modified Bentall-De Bono procedure and the comparison group consisted of 27 patients who underwent surgery according to the standard method. Results. Results of studies have shown that the proposed option for fixing the conduit made it possible to level the need for additional reinforcing sutures on the anastomosis line (from $48.1 \%$ with the classical Bentall-De Bono technique; $\mathrm{P}<0.001$ ), while the quality of the tightness of the anastomosis zone provided a decrease in the risk of postoperative bleeding with $33.3 \%$ to 4.2\% ( $\mathrm{P}<0.001)$. In both groups, after surgery, there was an equal tendency to improve echocardiographic parameters. Conclusion. In general, a comparative analysis of immediate results showed a decrease in the overall incidence of postoperative complications when using the proposed variant of conduit fixation from $37.0 \%$ to $9.9 \%(\mathrm{P}=0.002)$, which made it possible to reduce the overall mortality rate from $22.2 \%$ to $5.6 \%(\mathrm{P}=0.016)$.

\section{Original Article}

PII: S225199392100003-11

Rec. 19 February 2021

Rev. 13 March 2021

Acc. 25 March 2021

Keywords

Congenital heart

diseases,

Ascending aortic aneurysm,

Surgical treatment,

Quality of life

\section{INTRODUCTION}

In cardiovascular surgery, there are areas that are always considered extremely difficult even for specialized surgical clinics, including all types of aneurysms and dissections of the thoracic aorta. If we analyze the statistics, it will become clear that the increase in the total number of operations performed on the thoracic aorta is mainly due to the increase in interventions for aneurysms of the thoracic aorta [1]. This state of affairs is explained by a combination of the following reasons: among doctors, alertness about these diseases has significantly increased; the diagnostic capabilities have increased, allowing to recognize pathology at earlier stages before the development of fatal complications; an increase in the number of degenerative damage to the aortic wall associated with factors such as genetic abnormalities, atherosclerosis and hypertension [2].

Another important factor in the progress in the treatment of ascending aortic aneurysms, according to the opinion, is the success of a number of leading clinics in the treatment of this pathology, which has led to a sharp increase in surgical activity in many other cardiac surgery centers [3].

Throughout the history of the development of aortic aneurysm surgery, many methods have been proposed for replacing the affected segment [4]. However, the need to search for new materials for the formation of aortic prostheses is still relevant. Dacron valve-containing conduits are most often used for ascending aorta and aortic valve replacement [5]. Various methods of preoperative preparation of the Dacron tube have also been proposed to reduce bleeding, however, these techniques made the prosthesis rigid and more rigid, which made it difficult to create anastomoses, especially with the orifices of the coronary arteries [6].

Recent references are suggested on complications and reoperations in ascending aortic aneurysm shows that a leaky anastomosis is the cause of bleeding, and then the formation of pseudoaneurysms and fistulas. Along with the improvement and widespread use of artificial prostheses for replacing the affected aorta, another original direction, the use of biological tissue was further developed $[5,6]$. However, experience has shown that the problem of an "ideal" prosthesis has not yet been solved and it is necessary to continue the search for new options for implanting artificial conduits to prevent complications. 
The study was based on the results of surgical treatment of 98 patients with aneurysm ascending aorta AAA for the period from 2010 to 2020 . The patients were divided into two groups depending on the method of AAA prosthetics. The main group included 71 patients who underwent surgery according to an improved technique (Bentall-De Bono procedure), and the comparison group consisted of 27 patients who underwent surgery according to the standard technique.

\section{Ethical approval}

The review board and ethics committee of RSCS named after acad. V.Vakhidov approved the study protocol and informed consents were taken from all the participants.

\section{Distribution of patients depending on etiological factors}

The largest number of patients (58) were with atherosclerotic damage to the AAA, Marfan's syndrome occurred in 24 patients, 16 patients had congenital heart defects - (5 with coarctation of the aorta, 1 with ventricular, 3 with atrial septal defect and 7 patients with bicuspid aortic valve). When distributing patients by sex and age, it was noted that the majority of patients $(n=61)$ were aged 20-44 years. The average age in the main group was $32.5 \pm 1.6$ years and in the comparison group was $36.3 \pm 2.8$ years. Female patients predominated in all age categories $(n=72)$. The main percentage of patients in both the comparison group $(70.4 \%)$ and in the main group (66.2\%) was assigned to functional classes III and IV (25.9\% and 31.0\%, respectively) according to the New York Heart Association (NYHA) classification.

\section{Statistical Analysis}

Continuous data were analyzed using the unpaired Student's $t$ test, and categorical data were analyzed using the $\chi^{2}$ test or Fisher exact test. Values were expressed as mean \pm SD. A P value of less than 0.05 was considered significant. Statistical analysis was performed using the SPSS statistical software package (Version 11.5 for Windows, SPSS Inc.; Chicago, Ill).

\section{RESULTS AND DISCUSSION}

The main problem of the original Bentall-De Bono technique is the underestimation of the adequacy of the hemostatic component, especially when sealing the suture line when fixing the conduit to the fibrous ring of the aortic valve $(\mathrm{AV})$. A distinctive aspect of the proposed author's fixation of the conduit cuff to the fibrous ring of the aortic valve (Figure 1 ) is the following:

1. П-shaped suture is applied with the capture of the previous U-shaped suture with a step of $5 \mathrm{~mm}$ (provides maximum tightness and tightness of the prosthesis cuff to the fibrous ring of $\mathrm{AV}$, which minimizes bleeding and with systemic pressure).

2. After fixation of the conduit, the cuff of the prosthesis is sheathed over the free edge of the aortic wall with a continuous upholstery suture with 4-0 prolene suture (provides additional tightness and fixation of the aortic root).

The proposed technique provides additional hemostatic measures for the prevention of massive bleeding. The technical aspects of performing AAA posthetics are shown in Figure 2. Fixation of the conduit to the fibrous annulus of the aortic valve according to the classical method of Bentall De Bono operation in $48.1 \%$ (13 of 27 patients in the comparison group) of cases

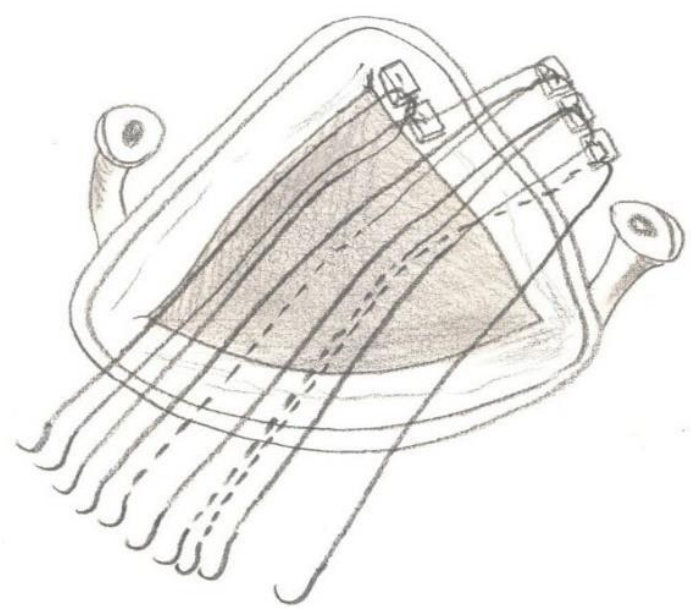

Figure 1. П-shaped suture when fixing the conduit to the fibrous ring of $\mathrm{AK}$ required the imposition of additional reinforcing sutures on the anastomosis line, while the proposed option due to two-row stitching allowed avoiding the need for performing this manipulation $\left(\chi^{2}=39.414 ; \mathrm{P}<0.001\right)$. At the same time, it was determined that the modified technical aspects of prosthetics of the ascending aorta did not lengthen the period of artificial circulation, and due to the absence of the need for additional stitching, the period of aortic occlusion was reliably reduced from $150.7 \pm 12.2$ to $120.7 \pm 4.0$ minutes $(t=2.34 ; P<0.05)$. 


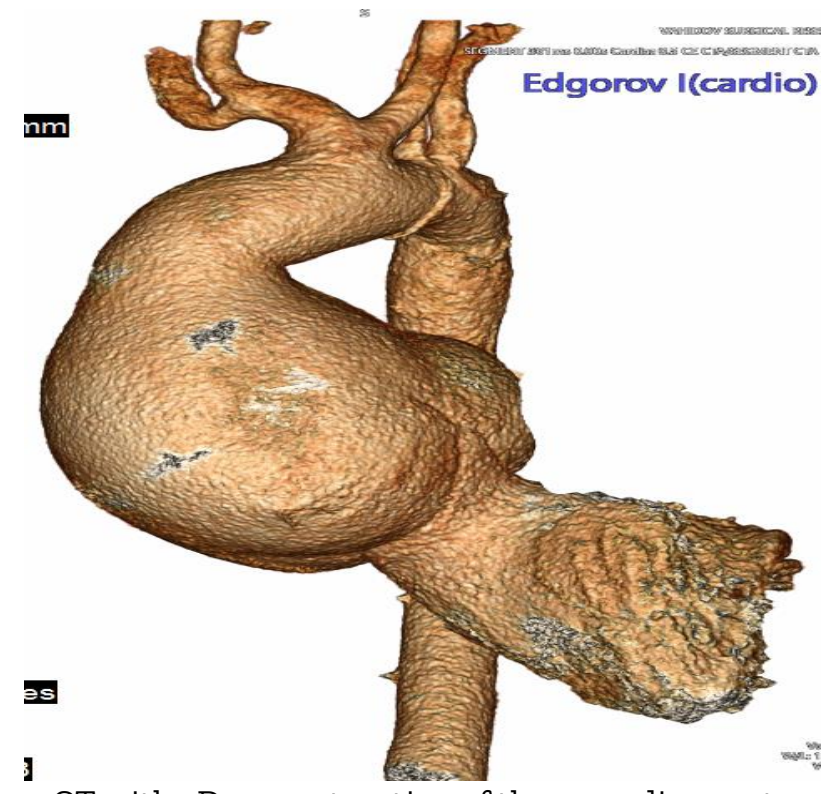

CT with 3D reconstruction of the ascending aorta

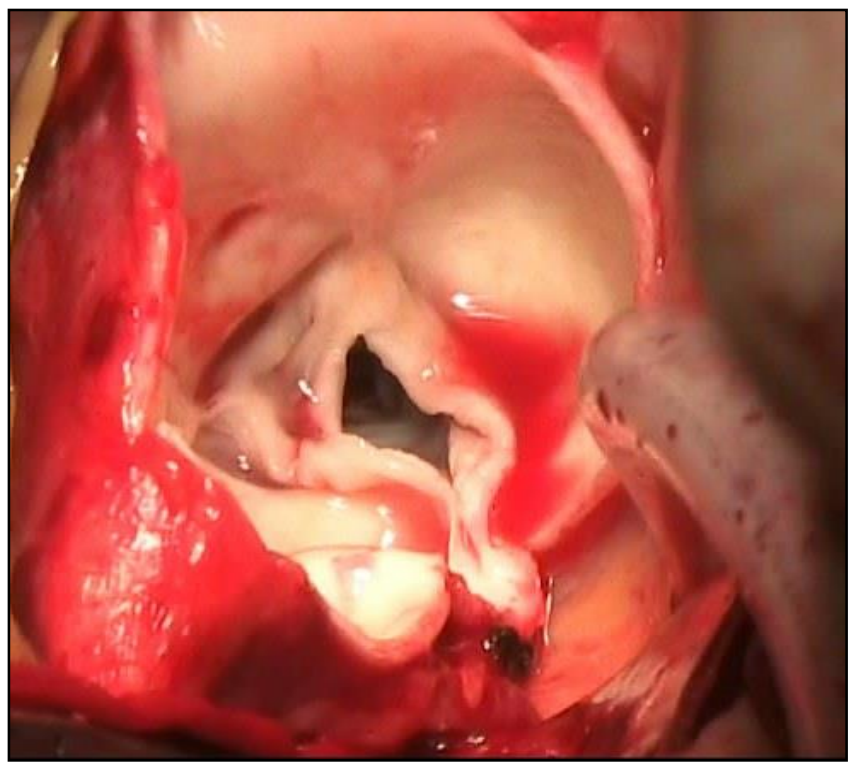

Opening an aneurysm

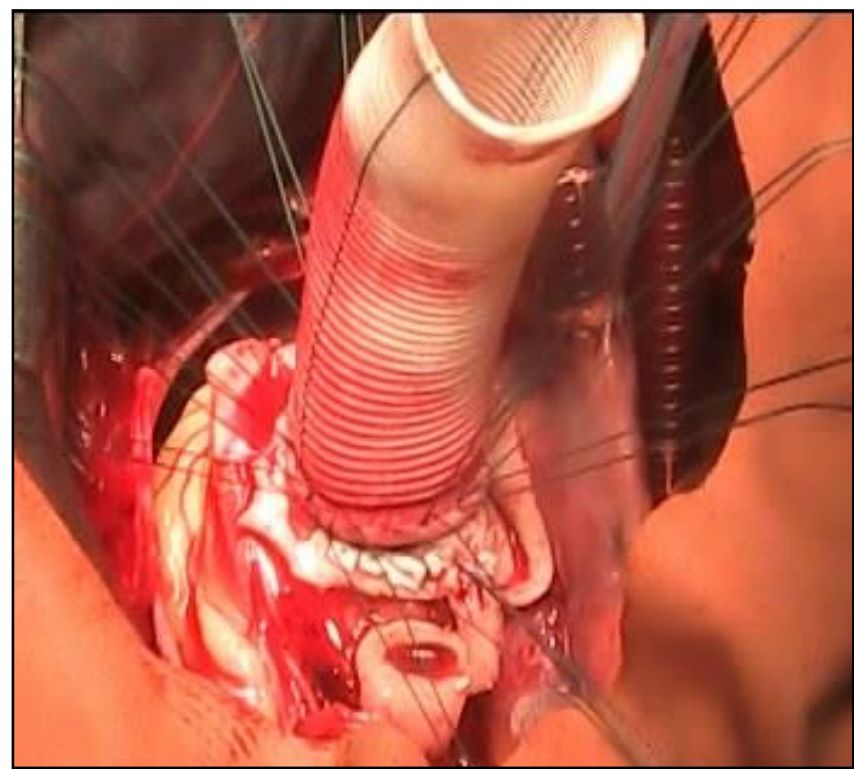

Formation of the proximal anastomosis

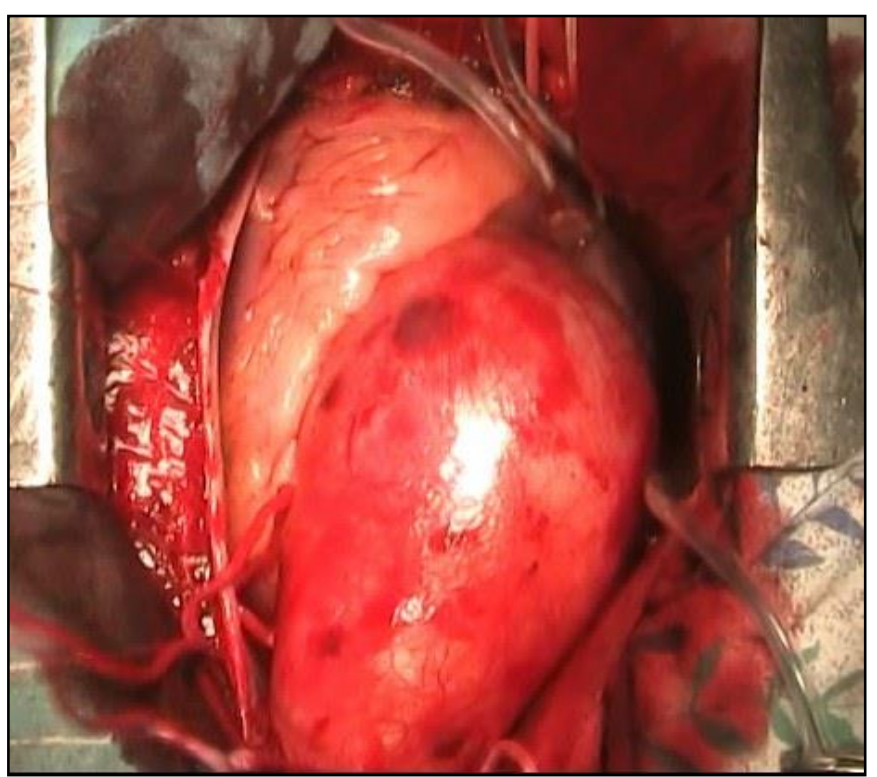

General view of the aneurysm

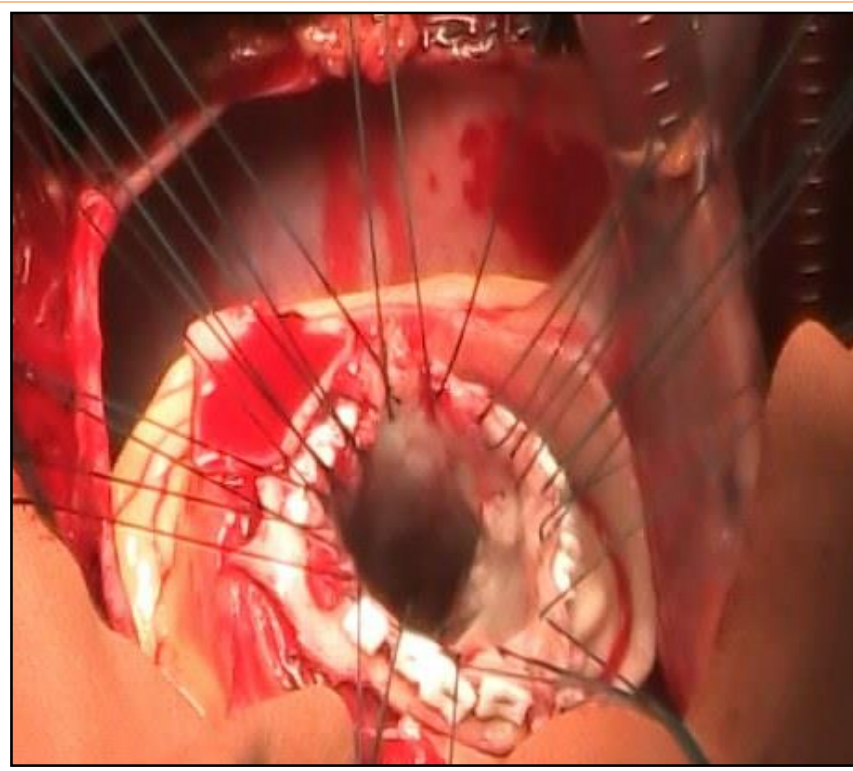

Preparation for fixing the conduit

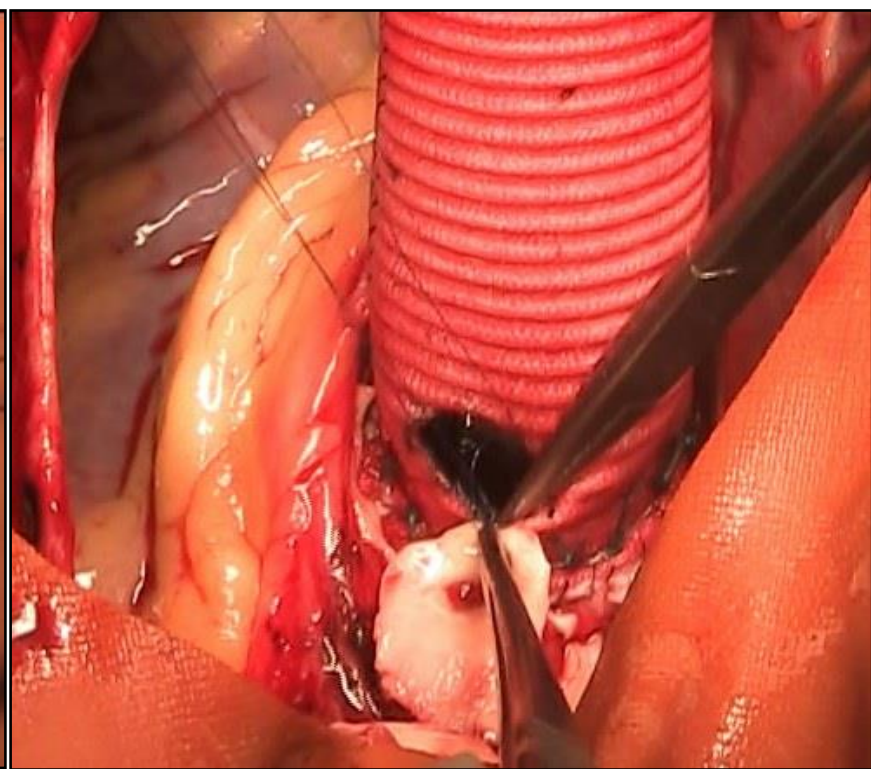

Coronary artery reimplantation

Citation: Abralov KhK, Murotov UA, Ibadov RA. Improvement in quality of life by surgical management of the ascending aortic aneurysm. J Life Sci Biomed, 2021; 11(2): 20-26. DOI: https://dx.doi.org/10.51145/jlsb.2021.3 


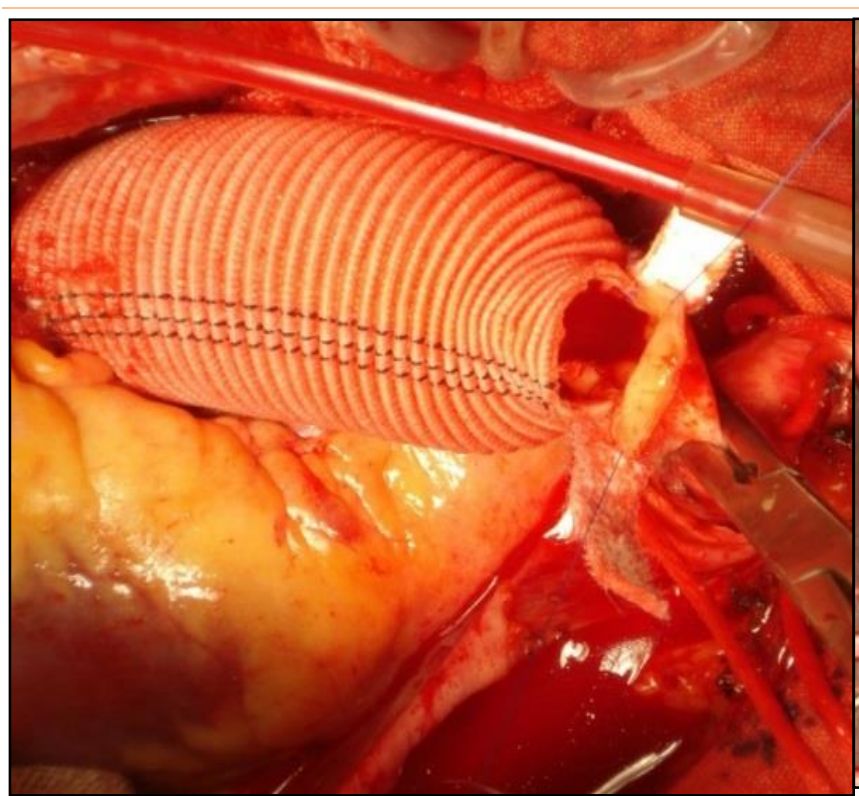

Distal anastomosis formation

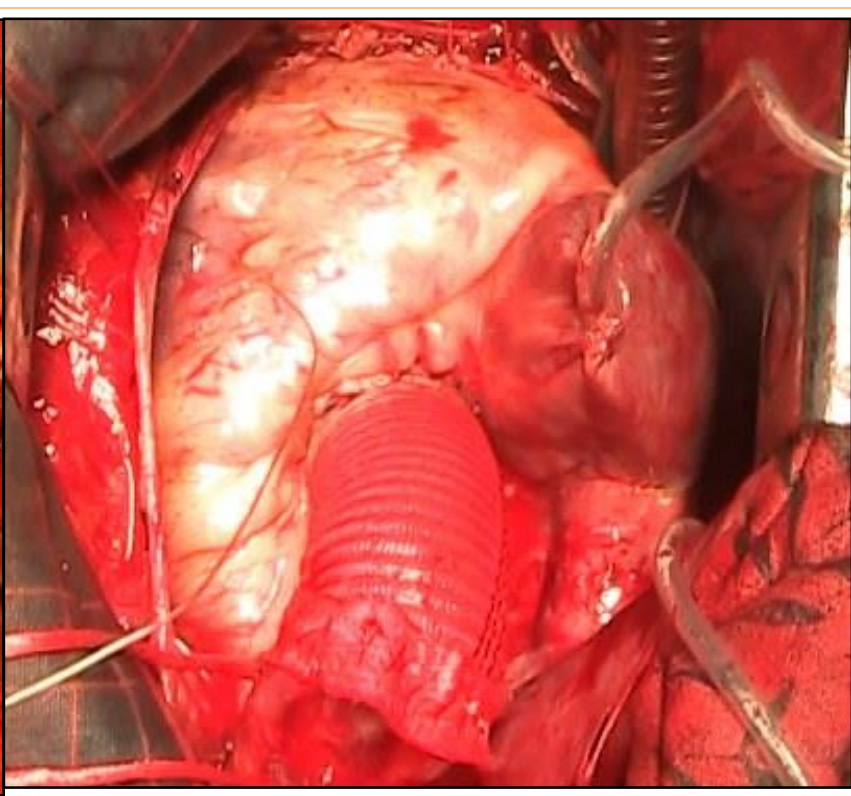

Completed type of reconstruction

Figure 2. Stages of prosthetics of the ascending aorta

Table 1. Structure and incidence of postoperative complications.

\begin{tabular}{|c|c|c|c|c|c|c|}
\hline \multirow{2}{*}{ Complications } & \multicolumn{2}{|c|}{ Comparison group } & \multicolumn{2}{|c|}{ Main group } & \multirow{2}{*}{$\chi^{2}(\mathrm{df}=1)$} & \multirow{2}{*}{$p$-value } \\
\hline & абс. & $\%$ & абс. & $\%$ & & \\
\hline Bleeding from the anastomotic area & 9 & $33.3 \%$ & 3 & $4.2 \%$ & 15.424 & $\mathrm{P}<0.001^{* *}$ \\
\hline Acute cardiovascular failure & 6 & $22.2 \%$ & 4 & $5.6 \%$ & 5.875 & $P=0.016^{*}$ \\
\hline Renal failure & 1 & $3.7 \%$ & 1 & $1.4 \%$ & 0.515 & $\mathrm{P}=0.473$ \\
\hline Liver failure & 2 & $7.4 \%$ & 2 & $2.8 \%$ & 1.053 & $\mathrm{P}=0.305$ \\
\hline Multiple organ failure & 2 & $7.4 \%$ & 1 & $1.4 \%$ & 2.372 & $\mathrm{P}=0.124$ \\
\hline Acute stroke & 1 & $3.7 \%$ & 1 & $1.4 \%$ & 0.515 & $\mathrm{P}=0.473$ \\
\hline Complete aortic valve (AV) block & 2 & $7.4 \%$ & 0 & $0.0 \%$ & 5.369 & $\mathrm{P}=0.021^{*}$ \\
\hline Mediastinitis & 1 & $3.7 \%$ & 1 & $1.4 \%$ & 0.515 & $\mathrm{P}=0.473$ \\
\hline Patients with complications & 10 & $37.0 \%$ & 7 & $9.9 \%$ & 10.077 & $\mathrm{P}=0.002^{* *}$ \\
\hline
\end{tabular}

*: P value $<0.05 i^{* *}$ : P value $<0.01$.

Table 2. Echocardiographic parameters on admission and after surgery.

\begin{tabular}{|c|c|c|c|c|c|c|c|}
\hline \multirow{3}{*}{ Indication } & \multicolumn{5}{|c|}{ Comparison group } & \multirow{2}{*}{\multicolumn{2}{|c|}{$\begin{array}{c}\text { Veracity between } \\
\text { groups }\end{array}$}} \\
\hline & \multirow{2}{*}{ Preoperative } & \multirow{2}{*}{ Postoperative } & \multicolumn{3}{|c|}{ Veracity } & & \\
\hline & & & Difference & $t$ & p-value & $\mathrm{t}$ & $p$-value \\
\hline $\mathrm{EDV}(\mathrm{ml})$ & $237.2 \pm 16.3$ & $160.9 \pm 11.3$ & $75.2 \pm 16.2$ & 4.64 & $\mathrm{P}<0.05^{*}$ & 0.26 & $\mathrm{P}>0.05$ \\
\hline ESV (ml) & $99.9 \pm 9.8$ & $77.1 \pm 6.8$ & $22.0 \pm 9.1$ & 2.41 & $\mathrm{P}<0.05^{*}$ & 0.74 & $\mathrm{P}>0.05$ \\
\hline $\mathrm{SV}(\mathrm{ml})$ & $133.6 \pm 8.6$ & $83.7 \pm 5.9$ & $48.4 \pm 9.2$ & 5.26 & $\mathrm{P}<0.05^{*}$ & 1.36 & $\mathrm{P}>0.05$ \\
\hline $\mathrm{EF}(\%)$ & $59.1 \pm 1.7$ & $52.8 \pm 1.4$ & $6.0 \pm 1.9$ & 3.18 & $\mathrm{P}<0.05^{*}$ & 0.87 & $\mathrm{P}>0.05$ \\
\hline \multirow{3}{*}{ Indication } & \multicolumn{5}{|c|}{ Main group } & & \\
\hline & \multirow{2}{*}{ Preoperative } & \multirow{2}{*}{ Postoperative } & \multicolumn{3}{|c|}{ Veracity } & & \\
\hline & & & Difference & $\mathrm{t}$ & $p$-value & & \\
\hline $\mathrm{EDV}(\mathrm{ml})$ & $224.9 \pm 13.4$ & $157.1 \pm 9.6$ & $55.2 \pm 6.9$ & 8.01 & $\mathrm{P}<0.05^{*}$ & & \\
\hline ESV (ml) & $99.9 \pm 7.1$ & $83.7 \pm 5.6$ & $23.9 \pm 5.8$ & 4.12 & $\mathrm{P}<0.05^{*}$ & & \\
\hline $\mathrm{SV}(\mathrm{ml})$ & $123.7 \pm 7.5$ & $95.2 \pm 6.0$ & $37.7 \pm 6.6$ & 5.71 & $\mathrm{P}<0.05^{*}$ & & \\
\hline $\mathrm{EF}(\%)$ & $57.1 \pm 0.9$ & $54.3 \pm 1.0$ & $2.5 \pm 1.7$ & 0.27 & $\mathrm{P}>0.05$ & & \\
\hline
\end{tabular}

EDV: end-diastolic volume; ESV: end systolic volume; SV: stroke volume; EF: ejection fraction; *: P value <0.05; **: P value <0.01. 
The total number of complications in the compared groups was noted in 17 cases: in 10 (37.0\%) patients from the comparison group and in 7 (9.9\%) patients in the main group $\left(\chi^{2}=10.077, \mathrm{P}=0.002\right)$ (Table 1$)$. The critical discharge volume (from $500 \mathrm{ml}$ and $>1000 \mathrm{ml}$ ) was observed in 12 (44.4\%) patients from the comparison group and in 6 (8.4\%) patients from the main group (Criterion $\left.\chi^{2}=25.677 ; \mathrm{df}=5 ; \mathrm{P}<0.01\right)$. Hemostasis in the comparison group was achieved by resternotomy in $22.2 \%$ of cases and conservatively in $11.1 \%$ of cases. In the main group of patients, resternotomy was performed in $2.8 \%$ of cases and in $1.4 \%$ of cases, hemostasis was achieved conservatively. The study of functional indicators of cardiac activity showed that in both groups, after performing prosthetics of the ascending aorta, there is an equal tendency to improve echocardiographic parameters, which objectively reflects the high efficiency of the interventions (Table 2).

The immediate postoperative mortality was observed in 6 (22.2\%) patients in the comparison group and in 4 (5.6\%) patients from the main group. Bleeding from the anastomotic area caused death in 4 (14.8\%) patients from the comparison group and in 1 (1.4\%) patient from the main group $(\chi 2=7.261 ; d f=1 ; P=0.008)$. Acute cardiovascular and multiple organ failure were the cause of death in one case (1.4\%) in patients from the main group; acute stroke in 2 (7.4\%) patients from the comparison group and in 1 (1.4\%) patient from the main group. 77.8\% were discharged from the comparison group and $94.4 \%$ from the main group.

The number of bed-days spent by the patients of the comparison group in the intensive care unit averaged $4.4 \pm 0.7$ days, and the duration of mechanical ventilation was $3.2 \pm 0.7$ days, while in the main group of patients these indicators averaged $2.4 \pm 0.3$ days and $1.4 \pm 0.2$ days, respectively $(t=2.43, P<0.05$ and $t=2.37, P<0.05)$. Cardiotonic support was used in the comparison group for an average of $3.0 \pm 0.6$ days, while in the main group this indicator was $1.5 \pm 0.2$ days $(t=2.10, P<0.05)$.

Thus, a comparative analysis of the immediate results of surgical treatment of aneurysm of the ascending aorta showed a decrease in the overall incidence of postoperative complications when using the proposed variant of conduit fixation from 37.0\% (10 patients) in the comparison group to 9.9\% (7 patients) in the main group ( $\left.\chi_{2}=10.077 ; \mathrm{P}=0.002\right)$, including against the background of hemorrhagic syndrome as a leading factor from $25.9 \%$ (7 patients) in the comparison group to $4.2 \%$ ( 3 patients) in the main group $(\chi 2=10.053 ; \mathrm{P}=0.002)$ and other complications from $11.1 \%$ (3 patients in the comparison group) to $5.6 \%$ (4 patients in the main group), which reduced the overall mortality rate from $22.2 \%$ to $5 \%$ (6 patients in the comparison group), 6\% (4 patients in the main group; $\chi^{2}=5.875 ; \mathrm{P}=0.016$ ); hemorrhagic syndrome as the main cause from $14.8 \%$ ( 4 patients in the comparison group) to $1.4 \%$ (1 patient in the main group; $\chi 2=7.261 ; \mathrm{P}=0.008$ ) and other complications from $7.4 \%$ ( 2 patients in the comparison group) to $4.2 \%$ (3 patients mostly group) and in general, increasing the proportion of patients discharged in a satisfactory condition from $77.8 \%$ (21 patients in the comparison group) to $94.4 \%$ (67 patients in the main group; $\chi 2=5.875 ; \mathrm{P}=0.016)$.

Long-term results were traced in 20 patients from the comparison group and in 67 patients from the main group. The follow-up period ranged from 6 months to 5 years. The distribution of patients after surgery by functional class according to NYHA showed that if initially in the comparison group and the main group, 19\% (4 patients) and 28.4\% (19 patients) were assigned to class IV, respectively to class III: 76.2\% (16) and 68.7\% (46), and to II: $4.8 \%$ (1) and 3.0\% (2), then after surgery grade O was detected in $42.9 \%$ (9) and $43.3 \%$ (29); grade I $52.4 \%$ (11) and $56.7 \%(38)$, and grade II only in $4.8 \%$ (1) patients in the comparison group.

\section{The results of surgical treatment were assessed according to the gradation}

Good results: no complaints, significant cardiac and circulatory disorders, restoration of working capacity, echocardiography showed a normal diameter of the ascending aorta and aortic valve prosthesis function, a decrease in the size of the heart, disappearance of signs of relative coronary insufficiency, improvement of myocardial contractile function.

\section{Satisfactory results}

After the operation, clinical improvement was noted, however, some complaints of recurrent pain in the heart, palpitations, and sometimes shortness of breath persisted; according to EchoCG, there was a positive dynamics of heart function indicators.

\section{Unsatisfactory results}

Given that all discharged patients showed a significant improvement in their condition, we included only patients with lethal complications in the early postoperative period in this group (Figure 3). 


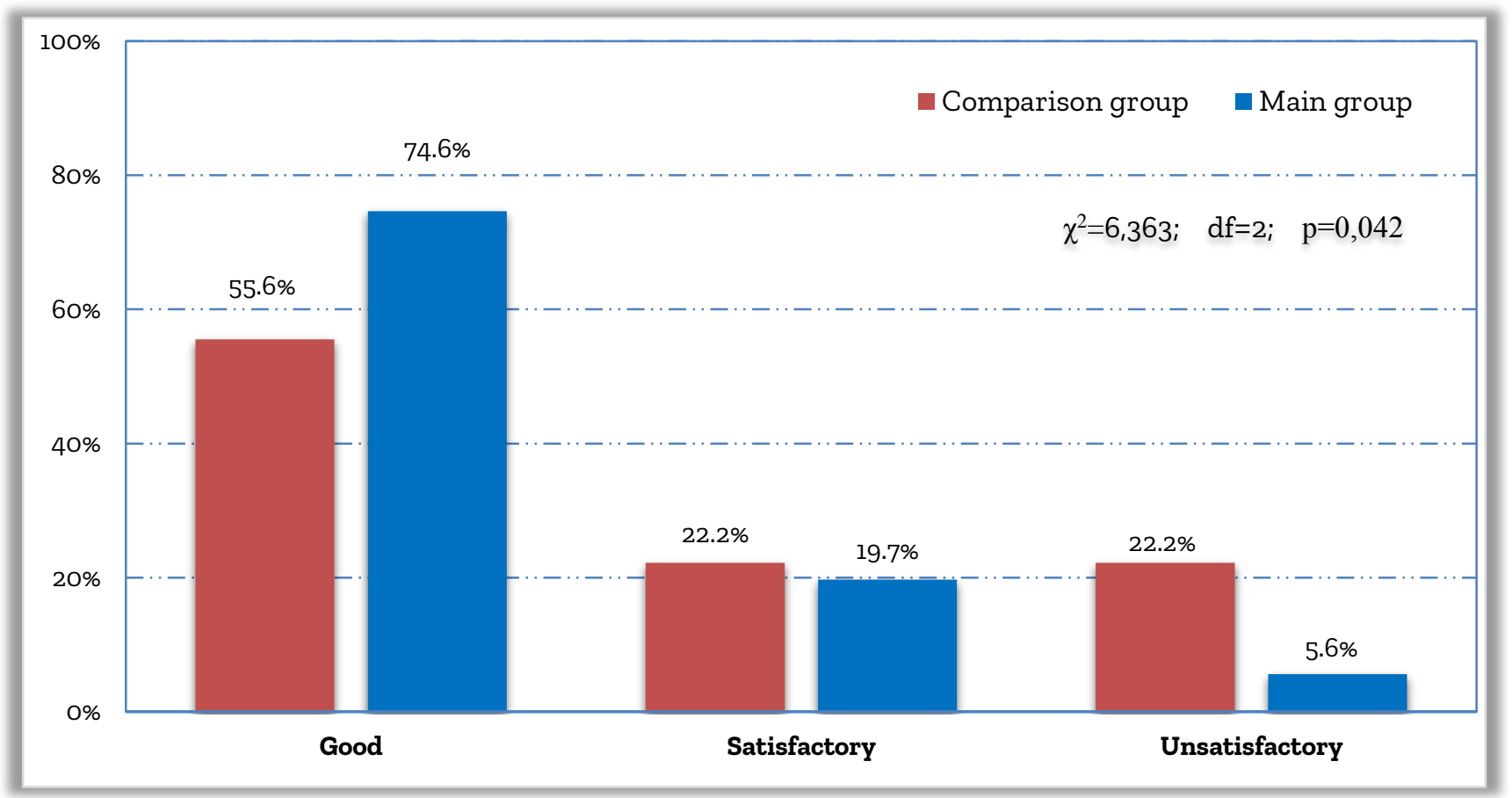

Figure 3. Summary results of prosthetics of the ascending aorta.

Thus, the proposed method of surgical treatment of aneurysm of the ascending aorta made it possible to increase the rate of good and satisfactory results of operations from $77.8 \%$ to $94.4 \%$ (in 21 out of 27 patients in the comparison group and in 67 out of 71 patients in the main group), which ensured regression of clinical and echocardiographic hemodynamic disorders with the transition of patients from NYHA functional class III-IV to class O-I, and also improved the quality of life of patients in the long-term period in relation to the initial values from $42.3 \pm 0.8$ to $73.8 \pm 0.4$ points $(t=44.49$; $\mathrm{P}<0.05)$ on the scale of physical well-being, from $41.9 \pm 0.6$ to $74.0 \pm 0.4$ points $(t=52.18 ; \mathrm{P}<0,05)$ on the scale of psychological well-being and in general on average across all domains from $42.1 \pm 0.6$ to $73.9 \pm 0.4$ points $(t=50.76, \mathrm{P}<0,05)$.

\section{CONCLUSION}

The proposed option for fixing the conduit made it possible to level the need for additional reinforcing sutures on the anastomosis line, while the quality of the tightness of the anastomosis zone provided a decrease in the risk of postoperative bleeding from $33,3 \%$ to $4.2 \%(\mathrm{P}<0.001)$, the volume of hemorrhagic discharge through the drainage from $735.2 \pm 111.5$ to $321.7 \pm 27.5 \mathrm{ml}(\mathrm{P}<0.001)$, the frequency of resternotomy from $22.2 \%$ to $2.8 \%$, conservative hemostasis from $11.1 \%$ to $1.4 \%$, providing in general an increase in the proportion of patients without hemorrhagic syndrome from $66.7 \%$ to $95.8 \%$ ( $\mathrm{P}<0.001$ ). In both groups, after performing prosthetics of the ascending aorta, there is an equal tendency to improve echocardiographic parameters, in particular, the EDV value decreased from $237.2 \pm 16.3$ to $160.9 \pm 11.3 \mathrm{ml}(\mathrm{P}<0.05)$ in the comparison group and from $224.9 \pm 13.4$ to

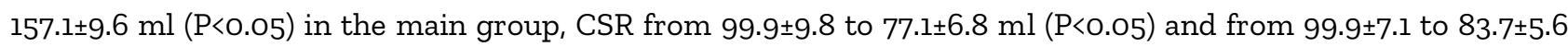
$\mathrm{ml}(\mathrm{t}=4.12 ; \mathrm{P}<0.05)$, respectively, SV from $133.6 \pm 8.6$ to $83.7 \pm 5.9 \mathrm{ml}(\mathrm{P}<0.05)$ and from $123.7 \pm 7.5$ to $95.2 \pm 6.0 \mathrm{ml}$ $(\mathrm{P}<0.05)$, which objectively reflects the high efficiency of the interventions.

Comparative analysis of the immediate results of surgical treatment of ascending aorta aneurysm showed a decrease in the overall incidence of postoperative complications when using the proposed variant of conduit fixation from $37.0 \%$ to $9.9 \%(\mathrm{P}=0.002)$, including against the background of hemorrhagic syndrome as a leading factor - from $25.9 \%$ to $4.2 \%(\mathrm{P}=0.002)$, which reduced the overall mortality rate from $22.2 \%$ to $5.6 \%(\mathrm{P}=0.016)$, including hemorrhagic syndrome as the main cause - from $14.8 \%$ up to $1.4 \%(\mathrm{P}=0.008)$.

\section{DECLARATIONS}

\section{Acknowledgements}

This work was supported by Republican Specialized Scientific and Practical Medical Center for Surgery named after academician V.Vakhidov, Tashkent, Uzbekistan 


\section{Competing interests}

The authors declare that they have no competing interests.

\section{REFERENCES}

1. Dobrowolski P, Klisiewicz A, Michalowska I, Kusmierczyk M, Hoffman P. Asymptomatic dissection of a giant aorta ascendens aneurysm in Turner syndrome. European Heart Journal. 2018; 39(14):1207. Article link | DOI: https://doi.org/10.1093/eurheartj/ehx652

2. Roussakis A, Calvi S, Raviola E, Albertini A. Patient with Unicuspid Aortic Valve and Ascending Aorta Aneurysm Treated with Ozaki Procedure and Ascending Aorta Replacement. Brazilian Journal of Cardiovascular Surgery. 2021 Feb;36(1):125-9. Article link | DOI: https://doi.org/10.21470/1678-9741-2020Ol50 ; PMID: 33355794.

3. Bakhutashvili Z, Janelidze L, Beria K, Matikashvili S, Limonjiani E. Aortic Arch Replacement without Deep Hypothermic Circulatory Arrest. Case Reports in Surgery. 2021; 2021:8821182. Article link | DOI: https://doi.org/10.1155/2021/8821182 | PMID: 33505758; PMCID: PMC7806363.

4. Ostovar R, Laux M, Kuehnel RU, Schroeter F, Braun C, Erb M, Albes JM. Immunosuppressive Agents and Thoracic Aortic Aneurysm: Real Correlation or Mere Coincidence? The Thoracic and cardiovascular surgeon. 2021 Jan 18. Article link | doi: https://doi.org/10.1055/s-0040-1721675 | PMID: 33461219.

5. Conti M, Romarowski RM, Ferrarini A, Stochino M, Auricchio F, Morganti S, Segesser LK, Ferrari E. Patientspecific computational fluid dynamics analysis of transcatheter aortic root replacement with chimney coronary grafts. Interactive CardioVascular and Thoracic Surgery. 2020 Dec 22: ivaa288. Article link | DOI: https://doi.org/10.1093/icvts/ivaa288 I PMID: 33351896.

6. Sekiya N, Ryomoto M, Tanaka H, Yamamura M, Yamashita K, Yajima S, Uemura H, Satoh A, Ueda D, Sakaguchi T. Graft Traction Resolved Left Ventricular Outflow Tract Obstruction. The Annals of Thoracic Surgery. 2020: So003-4975(20)32143-3. Article link | DOI: https://doi.org/10.1016/j.athoracsur.2020.09.073 | PMID: 33352177 . 